Canadian Studies in Population, Vol. 29.2, 2002, pp. 293-312

\title{
The Early Life Courses of Canadian Men: Analysis of Timing and Sequences of Events
}

\author{
Zenaida R. Ravanera \\ Rajulton Fernando \\ Thomas K. Burch
}

Population Studies Centre

University of Western Ontario

London, Ontario, Canada

\section{Celine Le Bourdais}

Centre interuniversitaire d'études démographiques

Institut national de la echerché scientifique (INRS) - Urbanisation

Montréal, Québec, Canada

\section{Abstract}

This paper focuses on the transition to adulthood of Canadian men born from 1916 to 1975. Through a life course framework, six early life events - school completion, work start, home-leaving, cohabitation, first marriage, and first birth - are examined using data from the 1995 Canadian General Social Survey of the Family. The trends in the timing and spread of each event, the length of transition to adulthood, and the trajectories to marriage indicate that the early life courses of Canadian men have changed tremendouslywith more diversifiedfamily behaviours and significant increases in ages at school completion and at start of regular work.

Key Words: transition to adulthood, life course, sequence analysis, event history 
Zenaida R. Ravanera, Rajulton Fernando, Thomas K. Burch and Celine Le Bourdais

\section{Résumé}

This paper focuses on the transition to adulthood of Canadian men born from 1916 to 1975. Through a life course framework, six early life events - school completion, work start, home-leaving, cohabitation, first marriage, and first birth - are examined using data from the 1995 Canadian General Social Survey of the Family. The trends in the timing and spread of each event, the length of transition to adulthood, and the trajectories to marriage indicate that the early life courses of Canadian men have changed tremendouslywith more diversifiedfamily behaviours and significant increases in ages at school completion and at start of regular work.

Key Words: transition to adulthood, life course, sequence analysis, event history

\section{Introduction}

In many societies, youth is recognized as a stage in a life course distinct from childhood and adulthood. Its beginning is biologically determined, with the onset of puberty, but its ending is culturally and socially defined and hence, more difficult to pinpoint. In Western culture, the end of schooling, the start of work, leaving the parental home, and family formation - usually through marriage - are events that mark the transition to adulthood. The experience of these events is mainly dependent on individual and family factors, but is also affected by historical, economic, cultural, and technological changes.

Early industrialization, for example, affected the patterns of residence, schooling, work, and marriage of the young in the mid-19th century Hamilton (Katz and Davey, 1978). It is interesting to note that the 'cluttered nest', a phenomenon noticed in Canada in the 1980s, also happened in Hamilton about a century ago. Using data from censuses, Katz and Davey showed that in 1851, one-half of young men had left home by age 17 whereas by 1871 , one-half had left only by age 22 . Employment in the city's newly established industries allowed the young to prolong their stay in their parental home.

Several historical, social, and economic upheavals in this century would have had as much, if not greater, impact on Canadian youth as the early industrializationhad in mid-19th century Hamilton. The Great Depression in the 30s, the Second World War, the post-war affluence, the turbulence in 60 s and early 70 s (including 
The Early Life Courses of Canadian Men:

Analysis of Timing and Sequence of Events

the women's liberation movement, introduction of the birth control pill, and sex revolution), and the economic recessions in the 80 s and 90 s have certainly affected the transition to adulthood. The results presented in this paper capture some of these historical influences on youth, and in particular, on the transition to adulthood of Canadian men born between 1916 and 1975.

In demography, we often study living arrangement, marriage, and birth but mostly as separate events. Canadian youth's leaving the parental homes, for example, has been the subject of a number of studies (Lapierre-Adamcyk, et al., 1995; Ravanera, et al., 1995; Zhao et al., 1995; Boyd and Norris, 1998; Mitchell, 1994; Gee et al., 1995; Beaupré and Le Bourdais, 1999). Changes in family formation, particularly the rise of cohabitation and later ages at first marriage and the timing of births in Canada have been studied as well (Lapierre-Adamcyket al., 1999; Le Bourdais and Marcil-Gratton, 1998, Ravanera, 1995).

While these studies are enlightening, there are merits in studying the various early life events simultaneously to get a more comprehensive picture of the transition to adulthood. The historical study of Katz and Davey (1978), for example, provides a good sense of the transition to adulthood in mid-nineteenth century Canada as they looked at schooling, work, marriage, and patterns of residence. Modell et al. (1976) made a study in the United States of the various early life events, comparing the youth in mid-19th century with those in the 1970s. And, Hogan (1981) analyzed the early life events of American men born between 1907 to 1952. A more recent study that examines the various events of school completion, regular work, home-leaving, and family formation is that of Ravanera et al. (1998), which focussed on Canadian women born in the period 1916 to 1975.

Adopting a similar approach to that taken in Ravanera et al. (1998), this paper focuses on Canadian men as the subject of study. Though youth of either gender go through similar events, recent research has shown that the experiences of males and females are different and hence, merit separate studies (Desrosiers et al., 1999a, 1999b). Through a life course framework, we look at six early life events - school completion, work start, home-leaving, cohabitation, first marriage, and first birth. We examine the timing and spread of each event, the length of transition to adulthood, and the trajectoriesto marriage, using data provided in the 1995 General Social Survey.

\section{Data: The 1995 General Social Survey of the Family}

The 1995 General Social Survey (GSS95) focussed on the family and gathered refined measures of timing, asking for both the year and month when life course events occurred $^{1}$ (Statistics Canada, 1997). The survey covers the whole of Canada, excluding residents of Yukon and Northwest Territories and full-time residents of institutions, with a total sample of 10750 individuals aged 15 and older. Although there were 4835 men respondents, this study is limited to 4390 men; we have excluded those aged 15 to 19 and 80 years or older at the time of the survey. Those aged 15-19 are too young to have experienced many of the events of interest here, 
Zenaida R. Ravanera, Rajulton Fernando, Thomas K. Burch and Celine Le Bourdais

and the few men who are 80 years and older are distributed over too wide an age range. To take into account the complexity of the sampling design, weights are used throughout all our analyses.

GSS95 suffers from limitations common to retrospective surveys. The first limitation is the inclusion in the survey of only those who have survived and have remained in the country as of survey date; that is, the respondents are, in effect, a select group. Another limitation is the problem of recalling events that happened in the past. This is especially true for older respondents who may have experienced certain events several years ago, and results in missing or erroneous information. A study by Courgeau (1992) shows that, compared to women, men are more prone to erroneous reporting of dates. While we have not systematically examined the biases brought about by these limitations, we think that in most instances, they are not substantial. In addition, the same study by Courgeau (1992) reports that erroneous dating of events does not affect (or only slightly affect) the sequence of events. In instances when the bias may be large, we include a note of caution in the presentation of our results.

\section{Methods: Life Tables and Event History Analysis}

We use various methods to examine changes and differencesin four aspects of early life transitions:(1) timing of transitions, (2) uniformity of ages at which the events are experienced, (3) length of cohort's transition to adulthood, and (4) trajectories to marriage. Central to the examination of changes over time is the analysis by birth cohorts, which allows for examination of the effects of historical changes. For analysis of the first three aspects, the sample sizes are large enough for grouping the respondents into 5-year birth cohorts from 1916-20 to 1971-75. For tracing the trajectories or pathways to marriage, we make use of 10-year birth cohorts for a total of 6 cohorts starting with the 1916-25 to the 1966-75 birth cohort.

\section{Timing of Transition and Age-Uniformity at Experiencing Events}

To examine change in timing of transitions over cohorts, we use the medians obtained through life table analysis ${ }^{2}$. Single-decrement life tables are done separately for school completion, start of regular work, home-leaving, first union ${ }^{3}$, first marriage, and for first birth for each 5-year birth cohort. The median is the age at which $50 \%$ in the cohort has experienced an event.

As an indicator of cohort's age homogeneity in experiencing each event, we use the interquartile range (IQR) or the difference between the ages at which $75 \%$ and $25 \%$ of the cohort has experienced an event. This provides the spread in the distribution of timing or the variation in the time it takes a cohort to experience an event. 
The Early Life Courses of Canadian Men:

Analysis of Timing and Sequence of Events

\section{The Length of Transition to Adulthood}

Transition to adulthood is not accomplished by simply undergoing an event but rather through a process involving various events. To measure the duration of transition from youth to adulthood, Hogan (1981) took the difference between the age at which $25 \%$ of a cohort completed schooling and the age at which $75 \%$ married. Modell et al. (1976) used the difference between the age at which $20 \%$ of a cohort completed schooling and the age at which $80 \%$ established their own home. Both measure the time when the first event in the overall process of transition to adulthood is well under way and the time when the last event is virtually completed for the cohort.

Of interest to researchers is the length of time it takes for the young to experience events associatedwith adulthood. The data on ages at experiencing the different life course events suggest that the transition to adulthood may be viewed in two phases: an early phase wherein the young start being independent and take off from their parental nests; and a later phase wherein they settle down and form their own families. As a measure of taking off, we subtracted the age at which $25 \%$ of a cohort started working (indicating that the process is well on the way) from the age at which $75 \%$ of the cohort leave the parental home ${ }^{4}$ (when the transition is virtually complete). For settling down, the starting point is the first quartile of leaving home and the terminal point is the third quartile of first union, first marriage, or first birth. In all these measures of length of transitions to adulthood, we confine our analysis to those who have experienced both the starting and terminal event of interest.

\section{Trajectories to Marriage: Probabilities of Sequences of Transitions}

Given that transition to adulthood involves a number of events, it is to be expected that there are myriad pathways towards adulthood. In this analysis, we looked into the different sequences of events leading to marriage. This is done through the use of LIFEHIST, a computer package for life history analysis (Rajulton, 1991). We use the non-Markovian portion of the program, which creates multiple-decrement life tables on the assumption that previous experiences of events affect subsequent transitions. LIFEHIST provides asymptotic probabilities of going through different sequences. These conditional probabilities of transitions are multiplied to obtain the probability of reaching first marriage through different pathways involving the other events of interest: school completion, entry into first job, home-leaving, first cohabitation, and first birth. 
Zenaida R. Ravanera, Rajulton Fernando, Thomas K. Burch and Celine Le Bourdais

\section{Results: Changes Over Cohorts}

\section{Timing of Transitions: The Median Ages}

Table 1 shows the life table estimates of ages at which the first quartile, second quartile (median), and third quartile of the cohorts experienced school completion, start of work, leaving the parental home, first union, first marriage, and first birth. The medians (Figure 1) are indicators of the average timing of occurrence of the events and provide a general picture of the trends over cohorts.

Except for the earlier cohorts, start of regular work, rather than school completion, seems to be experienced at the youngest age ${ }^{5}$. Over cohorts, there has been an increase in age at starting regular work. Fifty percent of those born between 192630 started working regularly by about 17.6 years, whereas among the $1966-70$ birth cohort, $50 \%$ did so only by age 20.7 , or an increase of 3 years in median age at work start. A similar trend is also apparent in age at school completion: on average, the 1926-30 birth cohort completed schooling by 17 years of age while the 1966-70 cohort did so by age 22.2 or an increase of about 5 years ${ }^{6}$.

Figure 1 clearly shows that the significant increase in end of schooling and start of work happened among those born between 1931 to 1945 . These cohorts entered their youth stage starting from the end of the Second World War and extending to the period of post-war affluence. Among the factors that may have contributed to the later age at end of schooling were the greater opportunities and the availability of resources to pursue higher education, which in turn delayed, for some, the start of regular work. It may also be that the returning soldiers and women, who entered the work force during the war, provided competition to these young men's search for first jobs. The continuing late age at start of work and end of schooling among the later cohorts may be due to a combination of factors: the slower economic growth, the restructuring of businesses, and the need for highly trained workers for jobs in the post-industrial economy.

Studies in the late $80 \mathrm{~s}$ and 90 s showing the cluttering of parental nests is apparent in the median ages at home-leaving (Boyd and Pryor, 1989; Boyd and Norris, 1995; Boyd and Norris, 1998; Beaupré and Le Bourdais, 1999). Compared to those born in the early 50s who left home at about 21.5 years of age, the latest cohorts are late home-leavers, staying home until about 23 years of age an increase of about a year and a half. But, the home-leaving pattern of the earlier cohorts reveals that the changes are not as dramatic as in school completion and work start. The age at home-leaving among those born before the 1950s hovered around 21 to 22 years. Interestingly, Katz and Davey (1978) found that in 1871 in Hamilton, Ontario, the median age at home-leaving of young men was also about 22 years while age at employment was around 15 years. Thus, a longer-term view points to significant changes in age at start of regular work and end of schooling but a more stable age at leaving the parental home.

The pattern of timing of family formation among men is a familiar U-shape: the early cohorts of men married and had their first child at relatively old ages, the 
The Early Life Courses of Canadian Men: Analysis of Timing and Sequences of Events

Table 1

Quartiles and Interquatile Ranges of Ages at Transitions By 5-year Birth Cohorts for Men, GSS95 Canada

\begin{tabular}{c||cccccccc}
\multicolumn{3}{c}{} & \multicolumn{3}{c}{ School Completion } & \multicolumn{3}{c}{ Start of Regular Work } \\
\hline Cohorts & $\begin{array}{c}\text { First } \\
\text { Quartile }\end{array}$ & Median & $\begin{array}{c}\text { Third } \\
\text { Quartile }\end{array}$ & $\begin{array}{c}\text { Inter- } \\
\text { quartile } \\
\text { Range }\end{array}$ & $\begin{array}{c}\text { First } \\
\text { Quartile }\end{array}$ & Median & $\begin{array}{c}\text { Third } \\
\text { Quartile }\end{array}$ & $\begin{array}{c}\text { Inter- } \\
\text { quartile } \\
\text { Range }\end{array}$ \\
\hline \hline & & & & & & & & \\
$1916-20$ & 16.2 & 20.2 & 26.2 & 10.0 & 17.2 & 19.9 & 25.8 & 8.6 \\
$1921-25$ & 15.5 & 17.6 & 23.3 & 7.8 & 16.1 & 18.2 & 22.7 & 6.6 \\
$1926-30$ & 14.8 & 17.0 & 22.6 & 7.8 & 16.0 & 17.6 & 20.9 & 4.9 \\
$1931-35$ & 15.8 & 20.3 & 29.3 & 13.5 & 15.9 & 17.8 & 21.6 & 5.7 \\
$1936-40$ & 16.0 & 20.2 & 30.1 & 14.1 & 16.1 & 18.4 & 21.4 & 5.3 \\
$1941-45$ & 18.0 & 22.2 & 29.5 & 11.5 & 17.5 & 19.8 & 22.8 & 5.3 \\
$1946-50$ & 18.3 & 22.2 & 26.5 & 8.2 & 17.9 & 19.4 & 22.4 & 4.5 \\
$1951-55$ & 18.4 & 21.8 & 26.5 & 8.1 & 18.1 & 19.9 & 22.9 & 4.8 \\
$1956-60$ & 18.5 & 22.1 & 26.6 & 8.1 & 17.9 & 19.9 & 22.9 & 5.0 \\
$1961-65$ & 18.6 & 22.3 & 26.4 & 7.8 & 17.7 & 19.9 & 23.3 & 5.6 \\
$1966-70$ & 18.9 & 22.2 & 25.1 & 6.2 & 18.6 & 20.7 & 23.6 & 5.0 \\
$1971-75$ & 18.9 & 21.5 & 23.7 & 4.8 & 18.3 & 20.4 & 23.6 & 5.3 \\
& & & & & & & & \\
\hline
\end{tabular}

\begin{tabular}{c||cccccccc}
\multicolumn{1}{c||}{} & \multicolumn{3}{c}{ Leaving the Parental Home } & \multicolumn{3}{c}{ Start of First Union } \\
\hline Cohorts & $\begin{array}{c}\text { First } \\
\text { Quartile }\end{array}$ & Median & $\begin{array}{c}\text { Third } \\
\text { Quartile }\end{array}$ & $\begin{array}{c}\text { Inter- } \\
\text { quartile } \\
\text { Range }\end{array}$ & $\begin{array}{c}\text { First } \\
\text { Quartile }\end{array}$ & Median & $\begin{array}{c}\text { Third } \\
\text { Quartile }\end{array}$ & $\begin{array}{c}\text { Inter- } \\
\text { quartile } \\
\text { Range }\end{array}$ \\
\hline \hline & & & & & & & & \\
$1916-20$ & 20.2 & 22.9 & 26.4 & 6.2 & 23.8 & 26.6 & 32.7 & 8.9 \\
$1921-25$ & 18.3 & 22.0 & 26.4 & 8.1 & 23.1 & 25.7 & 28.4 & 5.3 \\
$1926-30$ & 18.2 & 21.9 & 25.7 & 7.5 & 23.0 & 25.3 & 29.6 & 6.6 \\
$1931-35$ & 17.9 & 21.2 & 25.4 & 7.5 & 21.9 & 24.8 & 27.7 & 5.8 \\
$1936-40$ & 18.9 & 21.8 & 25.9 & 7.0 & 22.3 & 25.0 & 28.7 & 6.4 \\
$1941-45$ & 19.1 & 22.0 & 24.5 & 5.4 & 22.0 & 23.6 & 27.2 & 5.2 \\
$1946-50$ & 18.9 & 21.8 & 24.9 & 6.0 & 22.2 & 23.8 & 27.0 & 4.8 \\
$1951-55$ & 18.9 & 21.5 & 25.3 & 6.4 & 21.8 & 24.4 & 28.8 & 7.0 \\
$1956-60$ & 19.2 & 21.8 & 25.8 & 6.6 & 21.6 & 24.5 & 28.7 & 7.1 \\
$1961-65$ & 19.0 & 22.7 & 26.4 & 7.4 & 22.5 & 25.2 & 28.9 & 6.4 \\
$1966-70$ & 20.1 & 23.2 & 27.3 & 7.1 & 22.3 & 25.1 & & \\
$1971-75$ & 21.0 & 23.6 & & & 22.8 & & & \\
\hline
\end{tabular}

Start of First Marriage

Birth of First Child

\begin{tabular}{|c|c|c|c|c|c|c|c|c|}
\hline Cohorts & $\begin{array}{c}\text { First } \\
\text { Quartile }\end{array}$ & Median & $\begin{array}{c}\text { Third } \\
\text { Quartile }\end{array}$ & $\begin{array}{c}\text { Inter- } \\
\text { quartile } \\
\text { Range } \\
\end{array}$ & $\begin{array}{c}\text { First } \\
\text { Quartile }\end{array}$ & Median & $\begin{array}{c}\text { Third } \\
\text { Quartile }\end{array}$ & $\begin{array}{c}\text { Inter- } \\
\text { quartile } \\
\text { Range } \\
\end{array}$ \\
\hline $1916-20$ & 23.8 & 26.6 & 32.7 & 8.9 & 25.5 & 29.6 & 38.4 & 12.9 \\
\hline $1921-25$ & 23.1 & 25.7 & 28.4 & 5.3 & 25.4 & 28.8 & 35.9 & 10.6 \\
\hline $1926-30$ & 22.9 & 25.2 & 29.5 & 6.6 & 24.9 & 28.6 & 34.7 & 9.9 \\
\hline $1931-35$ & 22.0 & 25.0 & 27.9 & 5.9 & 24.0 & 27.3 & 33.3 & 9.3 \\
\hline $1936-40$ & 22.4 & 25.1 & 29.0 & 6.6 & 23.9 & 27.7 & 32.5 & 8.7 \\
\hline $1941-45$ & 22.1 & 23.6 & 27.4 & 5.3 & 23.9 & 26.5 & 31.4 & 7.5 \\
\hline $1946-50$ & 22.3 & 24.0 & 28.0 & 5.7 & 24.2 & 27.5 & 32.3 & 8.1 \\
\hline $1951-55$ & 22.3 & 25.6 & 32.8 & 10.5 & 25.0 & 29.3 & 38.5 & 13.5 \\
\hline $1956-60$ & 23.2 & 26.4 & 33.1 & 9.9 & 25.8 & 29.9 & 35.9 & 10.0 \\
\hline $1961-65$ & 24.7 & 28.7 & & & 27.0 & 31.2 & & \\
\hline $1966-70$ & 25.8 & & & & 26.6 & & & \\
\hline $1971-75$ & & & & & & & & \\
\hline
\end{tabular}


The Early Life Courses of Canadian Men: Analysis of Timing and Sequences of Events

Table 1

Quartiles and Interquatile Ranges of Ages at Transitions

By 5-year Birth Cohorts for Men, GSS95 Canada

\begin{tabular}{|c|c|c|c|c|c|c|c|c|}
\hline & \multicolumn{4}{|c|}{ School Completion } & \multicolumn{4}{|c|}{ Start of Regular Work } \\
\hline Cohorts & $\begin{array}{c}\text { First } \\
\text { Quartile }\end{array}$ & Median & $\begin{array}{c}\text { Third } \\
\text { Quartile }\end{array}$ & $\begin{array}{c}\text { Inter- } \\
\text { quartile } \\
\text { Range } \\
\end{array}$ & $\begin{array}{c}\text { First } \\
\text { Quartile }\end{array}$ & Median & $\begin{array}{c}\text { Third } \\
\text { Quartile }\end{array}$ & $\begin{array}{c}\text { Inter- } \\
\text { quartile } \\
\text { Range } \\
\end{array}$ \\
\hline $1916-20$ & 16.2 & 20.2 & 26.2 & 10.0 & 17.2 & 19.9 & 25.8 & 8.6 \\
\hline $1921-25$ & 15.5 & 17.6 & 23.3 & 7.8 & 16.1 & 18.2 & 22.7 & 6.6 \\
\hline $1926-30$ & 14.8 & 17.0 & 22.6 & 7.8 & 16.0 & 17.6 & 20.9 & 4.9 \\
\hline $1931-35$ & 15.8 & 20.3 & 29.3 & 13.5 & 15.9 & 17.8 & 21.6 & 5.7 \\
\hline $1936-40$ & 16.0 & 20.2 & 30.1 & 14.1 & 16.1 & 18.4 & 21.4 & 5.3 \\
\hline $1941-45$ & 18.0 & 22.2 & 29.5 & 11.5 & 17.5 & 19.8 & 22.8 & 5.3 \\
\hline $1946-50$ & 18.3 & 22.2 & 26.5 & 8.2 & 17.9 & 19.4 & 22.4 & 4.5 \\
\hline $1951-55$ & 18.4 & 21.8 & 26.5 & 8.1 & 18.1 & 19.9 & 22.9 & 4.8 \\
\hline $1956-60$ & 18.5 & 22.1 & 26.6 & 8.1 & 17.9 & 19.9 & 22.9 & 5.0 \\
\hline $1961-65$ & 18.6 & 22.3 & 26.4 & 7.8 & 17.7 & 19.9 & 23.3 & 5.6 \\
\hline $1966-70$ & 18.9 & 22.2 & 25.1 & 6.2 & 18.6 & 20.7 & 23.6 & 5.0 \\
\hline \multirow[t]{2}{*}{$1971-75$} & 18.9 & 21.5 & 23.7 & 4.8 & 18.3 & 20.4 & 23.6 & 5.3 \\
\hline & \multicolumn{4}{|c|}{ Leaving the Parental Home } & \multicolumn{4}{|c|}{ Start of First Union } \\
\hline Cohorts & $\begin{array}{c}\text { First } \\
\text { Quartile }\end{array}$ & Median & $\begin{array}{c}\text { Third } \\
\text { Quartile }\end{array}$ & $\begin{array}{c}\text { Inter- } \\
\text { quartile } \\
\text { Range } \\
\end{array}$ & $\begin{array}{c}\text { First } \\
\text { Quartile }\end{array}$ & Median & $\begin{array}{c}\text { Third } \\
\text { Quartile }\end{array}$ & $\begin{array}{c}\text { Inter- } \\
\text { quartile } \\
\text { Range }\end{array}$ \\
\hline $1916-20$ & 20.2 & 22.9 & 26.4 & 6.2 & 23.8 & 26.6 & 32.7 & 8.9 \\
\hline $1921-25$ & 18.3 & 22.0 & 26.4 & 8.1 & 23.1 & 25.7 & 28.4 & 5.3 \\
\hline $1926-30$ & 18.2 & 21.9 & 25.7 & 7.5 & 23.0 & 25.3 & 29.6 & 6.6 \\
\hline $1931-35$ & 17.9 & 21.2 & 25.4 & 7.5 & 21.9 & 24.8 & 27.7 & 5.8 \\
\hline $1936-40$ & 18.9 & 21.8 & 25.9 & 7.0 & 22.3 & 25.0 & 28.7 & 6.4 \\
\hline $1941-45$ & 19.1 & 22.0 & 24.5 & 5.4 & 22.0 & 23.6 & 27.2 & 5.2 \\
\hline $1946-50$ & 18.9 & 21.8 & 24.9 & 6.0 & 22.2 & 23.8 & 27.0 & 4.8 \\
\hline $1951-55$ & 18.9 & 21.5 & 25.3 & 6.4 & 21.8 & 24.4 & 28.8 & 7.0 \\
\hline $1956-60$ & 19.2 & 21.8 & 25.8 & 6.6 & 21.6 & 24.5 & 28.7 & 7.1 \\
\hline $1961-65$ & 19.0 & 22.7 & 26.4 & 7.4 & 22.5 & 25.2 & 28.9 & 6.4 \\
\hline $1966-70$ & 20.1 & 23.2 & 27.3 & 7.1 & 22.3 & 25.1 & & \\
\hline $1971-75$ & 21.0 & 23.6 & & & 22.8 & & & \\
\hline
\end{tabular}

\begin{tabular}{|c|c|c|c|c|c|c|c|c|}
\hline & \multicolumn{4}{|c|}{ Start of First Marriage } & \multicolumn{4}{|c|}{ Birth of First Child } \\
\hline Cohorts & $\begin{array}{c}\text { First } \\
\text { Quartile }\end{array}$ & Median & $\begin{array}{c}\text { Third } \\
\text { Quartile }\end{array}$ & $\begin{array}{c}\text { Inter- } \\
\text { quartile } \\
\text { Range }\end{array}$ & $\begin{array}{c}\text { First } \\
\text { Quartile }\end{array}$ & Median & $\begin{array}{c}\text { Third } \\
\text { Quartile }\end{array}$ & $\begin{array}{c}\text { Inter- } \\
\text { quartile } \\
\text { Range } \\
\end{array}$ \\
\hline $1916-20$ & 23.8 & 26.6 & 32.7 & 8.9 & 25.5 & 29.6 & 38.4 & 12.9 \\
\hline $1921-25$ & 23.1 & 25.7 & 28.4 & 5.3 & 25.4 & 28.8 & 35.9 & 10.6 \\
\hline $1926-30$ & 22.9 & 25.2 & 29.5 & 6.6 & 24.9 & 28.6 & 34.7 & 9.9 \\
\hline $1931-35$ & 22.0 & 25.0 & 27.9 & 5.9 & 24.0 & 27.3 & 33.3 & 9.3 \\
\hline $1936-40$ & 22.4 & 25.1 & 29.0 & 6.6 & 23.9 & 27.7 & 32.5 & 8.7 \\
\hline $1941-45$ & 22.1 & 23.6 & 27.4 & 5.3 & 23.9 & 26.5 & 31.4 & 7.5 \\
\hline $1946-50$ & 22.3 & 24.0 & 28.0 & 5.7 & 24.2 & 27.5 & 32.3 & 8.1 \\
\hline $1951-55$ & 22.3 & 25.6 & 32.8 & 10.5 & 25.0 & 29.3 & 38.5 & 13.5 \\
\hline $1956-60$ & 23.2 & 26.4 & 33.1 & 9.9 & 25.8 & 29.9 & 35.9 & 10.0 \\
\hline $1961-65$ & 24.7 & 28.7 & & & 27.0 & 31.2 & & \\
\hline $1966-70$ & 25.8 & & & & 26.6 & & & \\
\hline $1971-75$ & & & & 299 & & & & \\
\hline
\end{tabular}


Zenaida R. Ravanera, Fernando Rajulton, Thomas K. Burch and Céline Le Bourdais

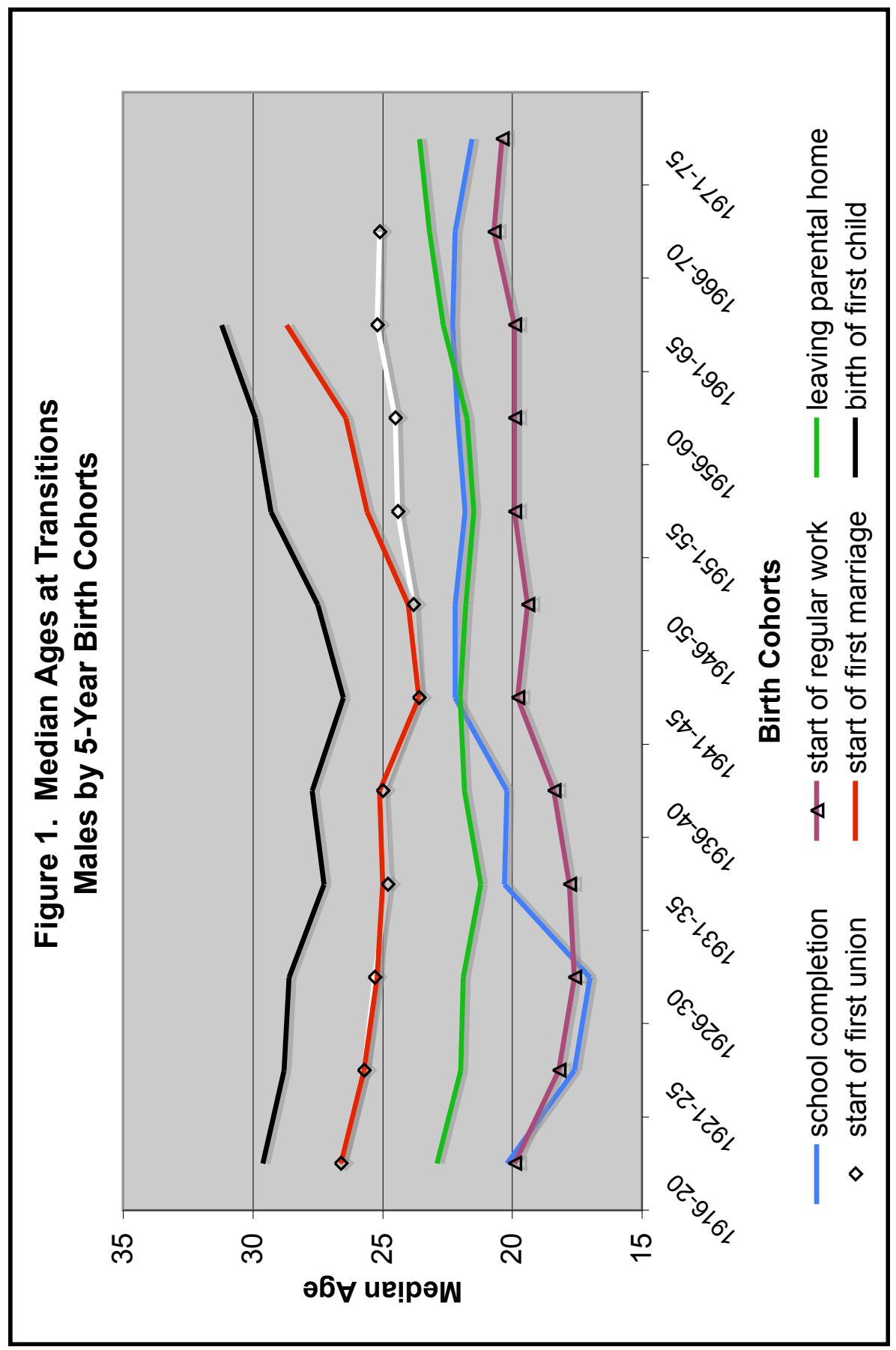


The Early Life Courses of Canadian Men:

Analysis of Timing and Sequence of Events

mid-cohorts at younger ages, and the later cohorts at older ages again. The median age at first marriage among the 1916-20 birth cohort was 26.6. This age gradually decreased to 23.6 among the 1941-45 birth cohort but increased in the next cohort and reached 28.7 for the 1961-65 birth cohort. Similarly, the age at first birth was high at 29.6 among the earliest cohort, decreased to a lowest of 26.5 among those born in 1941-45 and increasedagain reaching 31.2 among the 1961-65 birth cohort.

The marriage and fertility patterns early in the century was a continuation of what is known as a Western European pattern, that is, men experienced these events at relatively late ages. But family formation took a different turn among those who parented the boomers. Those born after 1920 initiated the trend of marrying and giving birth at younger ages, which continueduntil the pre-boomersor the 1941-45 birth cohort. Economic difficulties caused by the Great Depression of the 1930s and the upheavals brought about by the Second World War may have fostered values consistent with early family formation among these cohorts.

The boomers started the return back to the old pattern of late marriage and late parenthood and initiated a more dramatic change: cohabitation instead of marriage as the start of family formation. Figure 1 shows the divergence of median age at first union and at first marriage starting with the 1946-50 cohort, with a 0.2 year of difference. With the 1961-65 cohort, however, the gap between first union and first marriage is about 3.5 years, implying a great increase in the popularity of common-law unions, which for some was a prelude to marriage, and for others, a marriage replacement. These changes in timing and in cohabitation were part of the social changes that occurred around the late 60 s and early 70 s in Canada - among them, the women's liberation movement, the sex revolution, the introduction of the birth control pill - which, in part, may have been influenced by economic post war prosperity and the sheer large number of the boomers who were all young at that time.

\section{Uniformity in Age at Transitions: The Interquartile Ranges}

Table 1 also presents the interquartile ranges or the differences between the ages at which first and third quartile of the cohorts have experienced the various events. These ranges are measures of the spread of the age at occurrence of events and are indicators of the age homogeneity in experiencing each event. As Neugarten et al. (1965) remark, "(T)here exists what might be called a prescriptive timetable for the ordering of major life events: a time in the life span when men and women are expected to marry, a time to raise children, a time to retire" (p. 711). A comparison of IQRs among events show the largest spread for first birth in most cohorts and the smallest for age at start of work, indicating that young men are expected to start working (or need to work) within certain narrow age boundaries whereas there is more tolerance for variation in age at which to start a family.

The general trend in the IQRs seems to be similar to the trend in median ages, that is, the transitions are more spread among the early cohorts, concentrated in the mid-cohorts, and spread out again among the later cohorts. This trend particularly holds for the family life events of first union, first marriage, and first birth and to 
Zenaida R. Ravanera, Rajulton Fernando, Thomas K. Burch and Celine Le Bourdais

some extent, home-leaving. Interestingly, Modell et al. (1976) found that in comparison to about a century ago (about 1880), "young people today [1970s in the US] are more likely to be similar to one another in the age at which they leave home, enter marriage, and set up their own households" (p.17). They find this in agreement with the view that "this period of life has become more routinized". Similar routinization may have happened in Canada until about the 70s when the 1941-45 birth cohort reached adulthood. But, from that period and onwards to the 80s and 90s, ages at transition became less homogenized. Kohli (1986) noted a trend toward less age uniformity in family processes from the 1970s in other Western countries as well. This may be an indication that today's greater tolerance for different life styles extends to the timing of experiencing life events as well. The ages at which events are expected to happen are more widespread, or there may no longer be sanctions against deviation from age prescriptions.

The exception to this trend on the spread of timing of transition is that of completion of schooling. The interquartile ranges of transitions are very large for the cohorts born between 1931 to 1945 - about 11 to 13 years whereas those of the other cohorts are ten years or less. What may have been captured here is the return to schooling (for higher education or specialized training) of many members of these cohorts.

\section{Length of Transition to Adulthood: Taking Off and Settling Down}

Table 2 presents the number of years it took the cohorts to take off and settle down. A plot of length of transitions(Figure 2) shows that transition to adulthood was fairly stable until the 1936-40 cohort when both taking off and settling down (using the first union or first marriage as the terminal points) took about 10 years. A dramatic change occurred among men born after 1940: taking off became shorter; men were older when they started working but younger when they left home. The favourable economic conditions in the $60 \mathrm{~s}$ and $70 \mathrm{~s}$ (possibly with greater individual, familial, or societal resources) allowed longer stays in school and later work starts and made independent living possible at younger ages. The conditions during the 80 s were not conducive to this pattern of transitionanymore. Men born in the 60 s took slightly longer to take off. Many of them started to work later and also left parental homes later.

When first marriage is taken as the terminal event for settling down, the time to settle down among the more recent cohort is about as long as that among cohorts born before the $40 \mathrm{~s}$. But, when first union is taken as the terminal point, later cohorts take a shorter time and when first birth is the end point (until the 1956-60 cohort) a longer time. This indicates that the recent cohorts move through the transition faster when it is a question of informal commitment but more cautiously when the transition is to a more permanent state (first marriage and first birth). 
The Early Life Courses of Canadian Men:

Analysis of Timing and Sequence of Events

Table 2

Indicators of Length of Transition to Adulthood

By 5-Year Birth Cohorts

\begin{tabular}{lcccc}
\hline Cohorts & $\begin{array}{c}\text { 3Q HL } \\
\text { minus } \\
\text { 1Q WS }\end{array}$ & $\begin{array}{c}\text { 3Q FU } \\
\text { minus } \\
\text { 1Q HL }\end{array}$ & $\begin{array}{c}\text { 3Q FM } \\
\text { minus } \\
\text { 1Q HL }\end{array}$ & $\begin{array}{c}\text { 3Q FB } \\
\text { minus } \\
\text { 1Q HL }\end{array}$ \\
\hline & & & & \\
$\mathbf{1 9 1 6 - 2 0}$ & 10.0 & 9.5 & 9.5 & 14.0 \\
$\mathbf{1 9 2 1 - 2 5}$ & 9.8 & 9.6 & 9.5 & 12.1 \\
$\mathbf{1 9 2 6 - 3 0}$ & 9.7 & 10.2 & 10.3 & 12.3 \\
$\mathbf{1 9 3 1 - 3 5}$ & 9.6 & 9.3 & 9.3 & 11.8 \\
$\mathbf{1 9 3 6 - 4 0}$ & 9.5 & 9.3 & 9.4 & 11.2 \\
$\mathbf{1 9 4 1 - 4 5}$ & 6.8 & 7.3 & 7.4 & 10.4 \\
$\mathbf{1 9 4 6 - 5 0}$ & 6.5 & 7.4 & 7.9 & 11.2 \\
$\mathbf{1 9 5 1 - 5 5}$ & 6.7 & 8.9 & 9.6 & 12.7 \\
$\mathbf{1 9 5 6 - 6 0}$ & 7.0 & 8.4 & 9.6 & 12.5 \\
$\mathbf{1 9 6 1 - 6 5}$ & 7.9 & 7.9 & 9.6 & 11.1 \\
& & & & \\
\hline
\end{tabular}

3Q HL - Age at Home-Leaving of $75^{\text {th }}$ Percentile of Cohorts

1Q WS - Age at Start of Regular Work of $25^{\text {th }}$ Percentile of Cohorts

3Q FU - Age at First Union of $75^{\text {th }}$ Percentile of Cohorts

1Q HL - Age at Home Leaving of $25^{\text {th }}$ Percentile of Cohorts

3Q FM - Age at First Marriage of $75^{\text {th }}$ Percentile of Cohorts

3Q FB - Age at First Birth of $75^{\text {th }}$ Percentile of Cohorts

\section{Probabilities of Experiencing Trajectories to Marriage}

The parameters provided by life tables give a general picture of the average ages at which events were experienced by various cohorts but do not give the trajectories or pathways traversed by the members of the cohort. Table 3 (derived from the output of the LIFEHIST program) presents the probabilities of different trajectories leading to marriage ${ }^{7}$ for each of the 10 -year birth cohorts. There are several pathways towards marriage -- some marry without experiencing the other life events but most start working before marrying. The probabilities of direct marriage paths (A.1.- from origin to marriage, and A.2.- origin to home-leaving to marriage) were high (0.20) in the earliest cohort (1916-25) but these probabilities have substantially decreased in the subsequent cohorts with only 0.02 probability of occurrence in the 1966-75 birth cohort. 
Zenaida R. Ravanera, Fernando Rajulton, Thomas K. Burch and Céline Le Bourdais

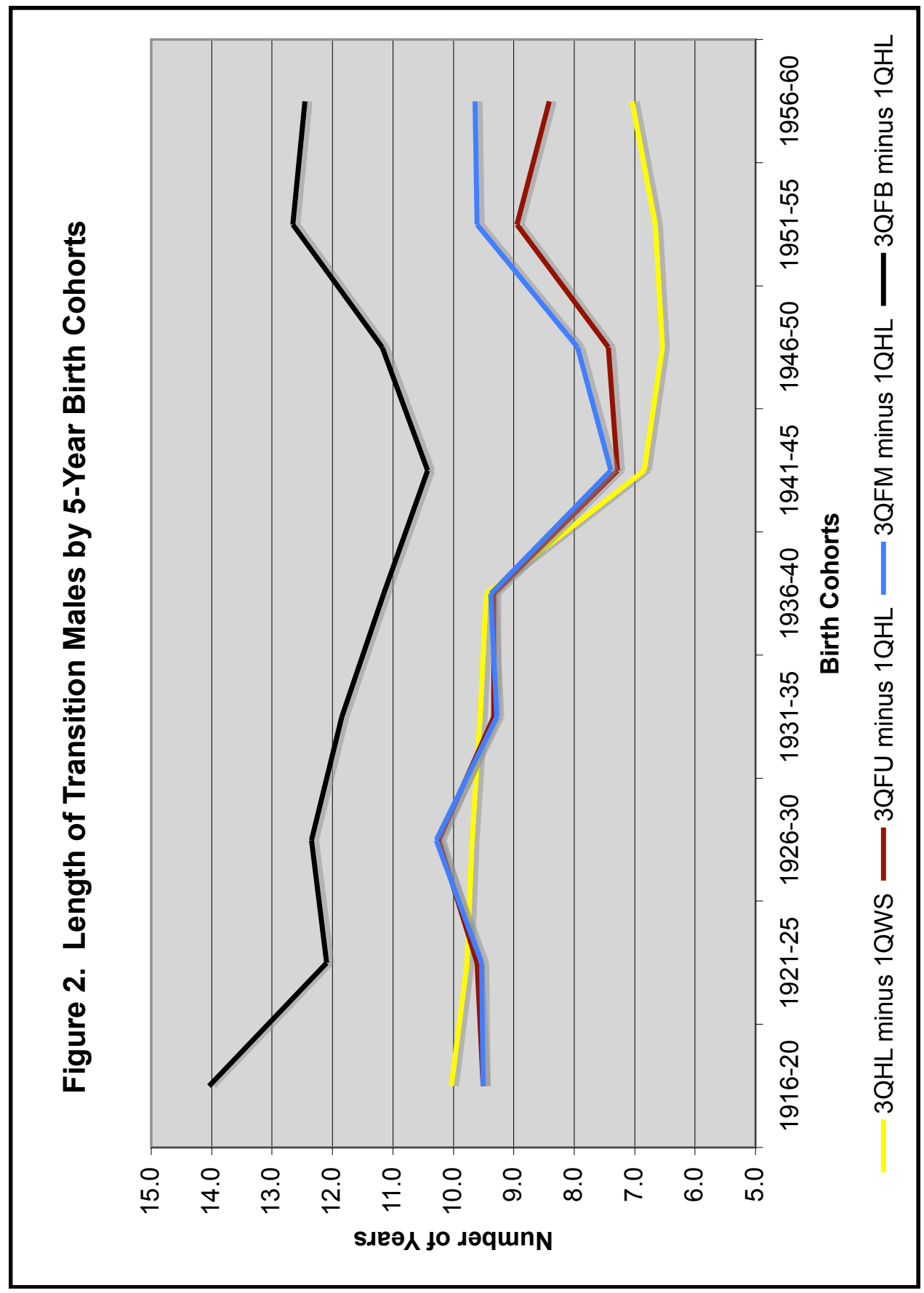


The Early Life Courses of Canadian Men:

Analysis of Timing and Sequence of Events

The more common path to marriage is through work, and for many through school completion too. Paths B1 to B3 all lead to marriage through work without school completion while $\mathrm{C} 1$ to $\mathrm{C} 3$ trace trajectories that involve both work start and end of schooling before marriage. Table 3 shows that the total probability of a trajectory to marriage through work without school completion was high at 0.17 among the 1916-25 birth cohorts, increased in the next two cohorts reaching 0.27 , and decreased again so that the probability is only 0.05 in the latest cohort. The men who followed this trajectory were most likely those who reached a certain level of education, got married, and resumed schooling or took higher education or specialized training later. Also, a large percentage of men (about $12 \%$ ), mostly among the earlier cohorts, did not provide their age at completion of schooling. The low probability in the later two cohorts is, to a great extent, due to men taking competing trajectories that end with cohabitation rather than marriage. The last two columns of Table 3 show that adding the probability of following a trajectory to cohabitation and then to marriage yields 0.11 probability in the latest cohort instead of just 0.05 . Even if union, rather than marriage, is the end point of these trajectories, the probabilities are still lower in the later cohorts indicating a reduced likelihood of marrying before school completion.

The most preferred trajectory leading to either marriage or union is the transition from origin to school completion to work start to home-leaving and then, marriage or union (Path C.2). The probabilities of this trajectory are the highest in all cohorts ranging from 0.25 to 0.28 . If one were to trace this trajectory leading to marriage alone, the probability is only 0.13 for the $1966-75$ cohort. This points to the increasing popularity of trajectories involving cohabitation.

The total of all these common trajectories towards marriage decreases from 0.75 in the earliest cohort to 0.52 in the $1956-65$ cohort and 0.27 in the latest. This is an indication of greater uniformity among the early cohorts and more diverse trajectories among the latest. The competing trajectories are mainly those involving cohabitation. When trajectories to cohabitation are included, total probabilities for the 1956-65 and 1966-75 cohorts are 0.71 and 0.59 respectively. The low probability for the 1966-75 birth cohort is affected by right censoring. Many members of this cohort, who are in the early part of their trajectories, will most likely experience the transition to marriage or union in the future and thereby increase this total probability.

\section{Discussion and Conclusion}

We have examined the events in the early lives of Canadian men born from 1916 to 1975 . These men would have spent their youth and made their transition to adulthood from about 1930s for the earliest cohort to the 1990s for the latest cohort, or a span of 60 years. Over this period, demographicbehaviour has changed significantly. Today's young men stay 5 years longer in school and start work 3 years later than the youth of 50 years ago. While we have mainly looked at the changes in timing, the nature of schooling and work have certainly changed as well, both reflecting the changes in the economic and social structures of the 


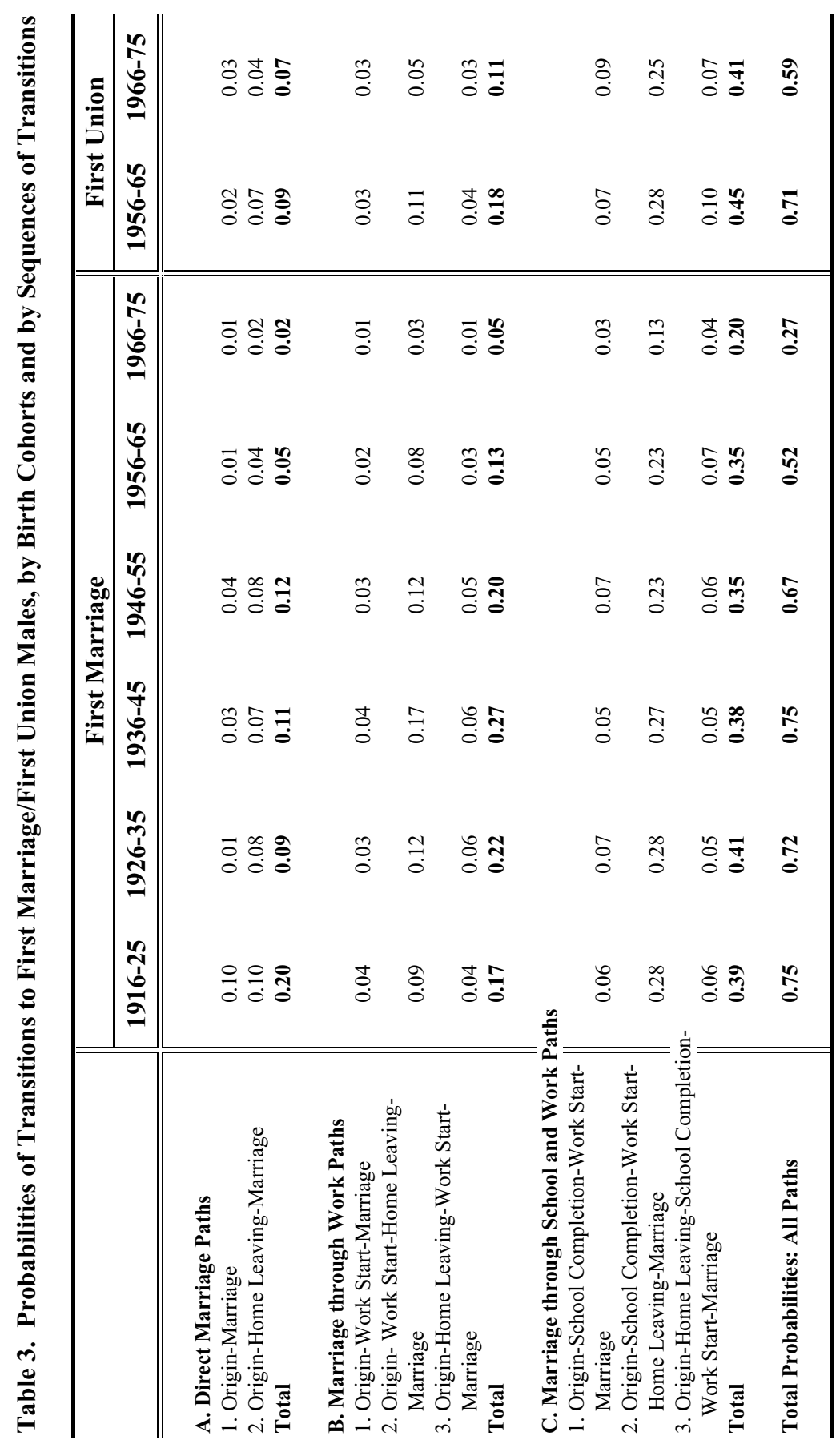


The Early Life Courses of Canadian Men:

Analysis of Timing and Sequence of Events

country over the period.

Family formation too has changed greatly. First, those born between the 1920s and 1940s married early and many did so within narrow age boundaries. Then, these trends were reversed starting with the baby boomers leading to the observed similarities between the earliest and most recent cohorts. The more recent cohorts picked up not only the reversal in timing initiated by the boomers but also the shift to cohabitation. This type of union is possibly the clearest indicator that families and family formation have undergone dramatic changes in the past 60 years. Cohabitation makes up 50\% of all unions formed among men born after 1965 and research has shown that, compared to marriage, cohabiting unions are more readily dissolved and lead to lower and later fertility (Balakrishnan et al., 1993; Wu, 2000).

Leaving the parental home seems to have undergone the least change. The age at home-leaving hovered around 21 to 22 years with the more recent cohorts leaving home just about a year later. But there are indications that the dependency relationship between parents and children has undergone changes as well. Prolonged schooling and later work start point to children's longer dependence on parents. And, the duration between starting work and leaving home was longer among the earlier cohorts indicating that they might have extended more help to their family of origin prior to starting their own family. The longer dependency among later cohorts is probably dictated by necessity engendered by changed economic structures but facilitated by parents' relative affluence and fewer children.

There is a preferred trajectory towards marriage traced by about $25 \%$ of men. This trajectory starts with school completion, then, start of work, then home-leavingand finally, marriage (or cohabitation, in the case of recent cohorts). It would be interesting to find out whether the likelihood of going through this trajectory differs by social status, culture, or community background, and whether following a less preferred trajectory affect later transitions in family life, such as divorce.

\section{Acknowledgement:}

The authors gratefully acknowledge funding support from the Social Sciences and Humanities Research Council of Canada and for the comments and suggestions of the reviewers.

\section{End Notes:}

1. The questions on dates of early life course events asked of most respondents were as follows: (1) Home-leaving: In what month and year did you last live with one or both of your parents (or parent substitutes?) (2) School completion: What is the highest level of education you have attained? In what month and year did you complete your studies? (3) First Regular Work: Have you ever worked at a job or business on a regular basis? By this I mean a full-time or part-time job which lasted six months or longer. In what year 
Zenaida R. Ravanera, Rajulton Fernando, Thomas K. Burch and Celine Le Bourdais

did you first start working on a regular basis? Exclude part-time employment while you were attending school full-time. (4) First Cohabitation: Have you ever been a partner in a common-law relationship? (Common-law partnership means having a sexual relationship while sharing the same usual address.) In what month and year did you and your partner begin to live together? (5) First Marriage: In what month and year was your first marriage? (6) Age at First Birth: In what month and year was your first child born?

Unlike the last 4 events, the first two are "renewable events" and are thus subject to right censoring, that is, the home-leaving may not in fact be the last as the respondents could return home, or the "highest" level of schooling may not be the highest as the respondents could take further education in the future. Another related issue is that the dates reported are not strictly similar for each respondent in that some may have left home or left school once and never returned whereas others may have left and returned home or to school a number of times.

2. Life table analysis has the advantage of taking care of right censoring of data. Those who have not experienced the event as of the survey date are taken into account in computations yielding unbiased probability estimates on the assumption that the censored cases would have experienced the event in the same way as those included in the survey.

3. Since common-law unions were not experienced by substantial numbers of older men, life tables for first union are constructed to make results for younger and older cohorts comparable. First union is taken as the age at the start of either first cohabitation or first marriage whichever occurred earlier. The difference in the probabilities of first union and first marriage would imply the probability of experiencing cohabitation.

4. In our earlier paper on early life transition of Canadian women (Ravanera, Rajulton, and Burch, 1998), we used end of schooling as the beginning event. This is because among women, the event that occurs earliest is school completion, whereas, for men, start of regular work is the earliest event experienced, on the average.

5. About $12 \%$ of men could not provide the age at school completion. It may well be that those who could not remember their age at school completion are those who have finishedschooling at younger ages, which would make the life table ages somewhat over-estimated. And, as the survey only asked the age at which the highest level of schooling was completed, this may also reflect the ages at completion of those who returned for higher level of schooling.

6. We have used as point of reference here the 1926-30 birth cohort because we think that there may be some bias in the estimate for the earlier birth cohorts (1916-25) in that those who had higher education may be over-represented in the sample. Given the differential mortality by social class, those who were alive as of the time of the survey among those aged 70 and over may be more 
The Early Life Courses of Canadian Men:

Analysis of Timing and Sequence of Events

representative of the higher social class, and hence would have had higher education and older age at school completion and work start. An alternative explanation for the very low age at school completion for the 1921-25 and 1926-30 birth cohorts is that the schooling of these young men may have been curtailed by the onset of World War II. A systematic examination of the war's effect on schooling needs to be done possibly with data other than the 1995 GSS.

As for the latest cohort, the slightly lower ages may be due to selection; that is, those who have already completed schooling and started working have done so at young ages not representative of the whole cohort. The estimate for this group may be higher if data are collected at a later time.

7. We could also have traced the pathways to first birth but we would have had to deal with several more trajectories.

\section{References:}

Balakrishnan, T.R., E. Lapierre-Adamcyk, K.K. Krotki. 1993. Family and Childbearing in Canada : A Demographic Analysis. Toronto :

University of Toronto Press. p. 139.

Beaupré, P. and C. Le Bourdais. 1999. Impact of Family and Sociodemographic Factors on Patterns of Leaving the Parental Home, Paper presented at the annual meeting of the Canadian Population Society, Lennoxvile (Québec).

Boyd, M. and E.T. Pryor. 1989. The Cluttered Nest: The Living Arrangements of Young Adults. Canadian Journal of Sociology 14:461-477.

Boyd, M. and D. Norris. 1995. The Cluttered Nest Revisited: Young Canadian Adults at Home in the 1990s. Working Paper WPS 95-127, Florida State University, College of Social Sciences.

Boyd, M. and D. Norris. 1998. Changes in the Nest: Young Canadian Adults Living with Parents, 1981-1996. Paper presented at the annual meeting of the Canadian Population Society, Ottawa.

Cooney, T.M. and D.P. Hogan. 1991. Marriage in an Institutionalized Life Course: First Marriage Among American Men in the Twentieth Century. Journal of Marriage and the Family 53 (Feb): 178-190.

Courgeau, D. 1992. Impact of Response Errors on Event History Analysis. Population: An English Selection, 4:97-110. 
Zenaida R. Ravanera, Rajulton Fernando, Thomas K. Burch and Celine Le Bourdais

Desrosiers, H., H. Juby and C. Le Bourdais. 1999a. Female Family Paths. In Y. Péron et al. (eds.), Canadian Families at the Approach of the Year 2000. Statistics Canada, Census monograph series, (Cat. 96-321-MPE). Ottawa : 101-153.

Desrosiers, H., H. Juby and C. Le Bourdais. 1999b. Male Family Paths. In Y. Péron et al. (eds.), Canadian Families at the Approach of the Year 2000. Statistics Canada, Census monograph series, (Cat. 96-321-MPE). Ottawa : $155-206$

Dumas, J. and Y. Peron. 1992. Marriage and Conjugal Life in Canada, Current Demographic Series, Statistics Canada (Cat. No. 91-534E). Ottawa.

Elder, G.H. Jr. 1978. Family History and the Life Course. In T. Hareven (ed) Transitions: The Family and the Life Course in Historical Perspective; Academic Press. Pp.17-64

Elder, G.H. and A. Caspi. 1990. Studying Lives in a Changing Society: Sociological and Personological Explorations. In A.I. Rabin, R.A. Zucker, R.A. Emmons and S. Frank (eds) Studying Persons and Lives. New York: Springer Publishing Co. Pp. 201-247.

Gee, E. M., B.A. Mitchell, A.V. Wister. 1995. Returning to the Parental "Nest": Exploring a Changing Canadian Life Course. Canadian Studies in Population 22(2). Pp. 121-144.

George, L.K. 1993. Sociological Perspectives on Life Transitions. Annual Review of Sociology 19:353-73.

Hareven, T.K. 1980. The Life Course and Aging in Historical Perspective. In K.W. Back (ed) Life Course: Integrative Theories and Exemplary Population. Boulder, Colorado: Westview Press. Pp.9-25.

Hareven, T.K. 1991. The History of Family and the Complexity of Social Change. American Historical Review 96(1):95-124.

Hogan, D.P. 1981. Transitions and Social Change: The Early Lives of American Men. NY: Academic Press.

Imhof, A.E. 1986. Life-Course Patterns of Women and Their Husbands: 16th to 20th Century. In A.B. Sorensen, F.E. Weinert, and L.R. Sherrod (eds) Human Development and the Life Course: Multidisciplinary

Perspectives. New Jersey: Lawrence Erlbaum Associates. Pp. 247-270.

Katz, M.B. and I.E. Davey. 1978. Youth and Early Industrialization in a Canadian City. American Journal of Sociology, 84 (Supplement) S81S119. 
The Early Life Courses of Canadian Men:

Analysis of Timing and Sequence of Events

Kohli, M., 1986. The World We Forgot: A Historical Review of the Life Course. In V.W. Marshall (ed) Later Life: The Social Psychology of Aging. Sage Publications, California. Pp. 271-303.

Lapierre-Adamcyk, E., C. Le Bourdais and K. Lehrhaupt, 1995. Le départ du foyer parental des jeunes Canadiens nés entre 1921 et 1960. Population 50(4-5): 1111-1136.

Lapierre-Adamcyk, E., C. Le Bourdais and N. Marcil-Gratton. 1999. Vivre en couple pour la première fois. La signification du choix de l'union libre au Québec et en Ontario. Cahiers québécois de démographie 28 (1-2): 199-227.

Le Bourdais, C. and N. Marcil-Gratton. 1998. The Impact of Family Disruption in Childhood on Demographic Outcomes in Young Adulthood. In M. Corak (ed.), Labour Markets, Social Institutions, and the Future of Canada's Children. Statistics Canada and Human Resources Development. Ottawa : 91-105.

Mitchell, B. A. 1994. Family Structure and Leaving the Nest: A Social Resource Perspective. Sociological Perspectives 37(4). Pp. 651-671.

Modell, J., F.F.Furstenberg, Jr., and T.Hershberg. 1976. Social Change and Transitions to Adulthood in Historical Perspective. Journal of Family History 1(1):7-32.

Modell, J. and T.K. Hareven. 1978. Transitions: Patterns of Timing. In T.K. Hareven (ed) Transitions: The Family and the Life Course in Historical Perspective. Academic Press. Pp. 245-269.

Neugarten, B.L., J.W. Moore, J.C. Lowe. 1965. Age Norms, Age Constraints, and Adult Socialization. The American Journal of Sociology, 70: 710-717.

Poulain, M., B. Riandey, J. Firdion. 1992. Data from a Life History Survey and from the Belgian Population Register: A Comparison. Population: An English Selection, 4:77-96.

Rajulton, F. 1991. Life History Analysis: Guidelines for Using the Computer Package LIFEHIST. Population Studies Centre, The University of Western Ontario, London, Canada.

Ram, B. 1990. New Trends in the Family: Demographic Facts and Features. Current Demographic Analysis Series, Statistics Canada (Cat. No. 91535E). Ottawa

Ravanera, Z.R., F. Rajulton, and T.K. Burch. 1995. A Cohort Analysis of Home-Leaving in Canada, 1910-1975. Journal of Comparative Family Studies 26(2). Pp. 179-194. 
Zenaida R. Ravanera, Rajulton Fernando, Thomas K. Burch and Celine Le Bourdais

Ravanera, Z.R. 1995. A Portrait of the Family Life of Young Adults. In J. Dumas (ed), Family Over the Life Course. Current Demographic Analysis Series, Statistics Canada (Cat. No. 91-543E). Ottawa: 7-35.

Ravanera, Z.R., F. Rajulton, and T.K. Burch. 1998. Early Life Transitions of Canadian Women: A Cohort Analysis of Timing, Sequences, and Variations. European Journal of Population 14: 179-204.

Statistics Canada. 1997. 1995 General Social Survey, Cycle 10: The Family, Public Use Microdata File Documentation and User's Guide. Catalogue No. 12M0010GPE, Ministry of Industry. Ottawa.

Wu, Z. 2000. Cohabitation: An Alternative Form of Family Living. Don Mills: Oxford University Press. Pp. 131-36.

Zhao, J., F. Rajulton, and Z.R. Ravanera. 1995. Leaving Parental Homes in Canada: Effects of Family Structures, Gender and Culture. Canadian Journal of Sociology 20(1). 